300

The Open Psychology Journal

RESEARCH ARTICLE

\title{
Effect of Attachment and Personality Styles on the Ability to Interpret Emotional Vocal Expressions: A Cross-sectional Study
}

\author{
Anna Esposito ${ }^{1,2}$ and Alda Troncone $e^{1, *(D)}$

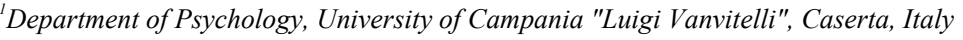 \\ ${ }^{2}$ International Institute for Advanced Scientific Studies (IIASS), Vietri sul Mare, Salerno, Italy
}

\begin{abstract}
:
Background:

Taking attachment as its theoretical reference, the post-rationalist approach within cognitive theory has outlined two basic categories of the regulation of cognitive and emotional processes: the outward and inward personality orientations. Research on the role of attachment style in individuals' ability to decode emotions has never considered inward and outward orientations.

Objective:

This cross-sectional study was conducted to compare individuals with different attachment styles and different inward/outward personality organizations on their ability to decode vocal emotions.

Methods:

After being assessed for attachment and personality styles, a sample of university students performed an emotional-decoding task, and their accuracy (Study 1) and reaction time (Study 2) was measured. Gender effects were also examined.

Results:

No significant differences in emotion decoding accuracy emerged among individuals with either secure or insecure attachment styles and either inward or outward personality orientations. Both secure and inward individuals were significantly faster than insecure and outward ones in decoding vocal expressions of joy, whereas securely attached individuals were faster than insecure ones in decoding vocal expressions of anger.

Conclusion:

Considering that the recognition of emotion falls within the basic skills upon which typical social interactions are based, the findings can be useful to enhance the comprehension of personality-related factors involved in the context of daily social interactions.
\end{abstract}

Keywords: Attachment styles, Personality styles, Inward and outward orientations, Vocal emotions, Reaction time, Emotions recognition.

\begin{tabular}{|l|l|l|r} 
Article History & Received: April 26, 2020 & Revised: July 27, 2020 & Accepted: August 05, 2020
\end{tabular}

\section{INTRODUCTION}

In one of the earliest contributions to attachment theory, Bowlby $[1,2]$ observed that attachment relationships are processes guided by emotional exchanges, and they affect how informational processing of emotional messages is regulated [ 3 - 5]. In particular, research has shown that the ability of an individual to decode emotions in others - a skill developed during the first 6-7 months of life $[6,7]$-is influenced by their

\footnotetext{
* Address correspondence to this author at the Department of Psychology, University of Campania "Luigi Vanvitelli", Caserta, Italy; Tel: +39 0823274768 ; E-mail: alda.troncone@unicampania.it
}

attachment style, which, in turn, influences one's comprehension of emotions later in life [8,9].

Previous works have examined factors believed to be responsible for adults' ability to recognize emotions, including age [10], specific personality dimensions [11], relationship well-being [12], alexithymia, and repressive coping style [13]; several of their findings suggest that securely attached adults can recognize and label emotional facial expressions better than insecurely attached adults [14 - 17]. Nevertheless, no consensus has been reached on how insecure attachment affects the ability to recognize facial emotional expressions $[15,18$ - 
20]. While some literature on emotional competence development has shown that children with disorganized attachment are disadvantaged in emotion regulation strategies $[21,22]$, and results on their ability to discriminate among emotions are mixed [23].

It should be noted that most research into the relationship between attachment style and ability to recognize emotional expressions (including those mentioned above) have relied solely on facial emotional stimuli. Consequently, how individuals with different attachment styles differ in perceiving emotions conveyed by vocal stimuli is a topic that remains unexplored. Still, as evidence suggests [24], inferences about emotional states depend on the communication mode (e.g., audio only, video only, combined audio and video) through which emotional states are conveyed. In this regard, detection of affect from audiovisual stimuli (composite face-voice stimuli) has been described as emerging earlier than the ability to perceive emotions from faces alone [25]. As with physical facial features, combinations of various vocal characteristics (e.g., pitch, speech intensity) allow individuals to infer others' emotional processes [26]. In addition, emotion recognition in voices alone was found to continuously improve from early childhood to mid-adolescence [27] and to differ from emotion recognition in facial expressions because the brain processes auditory signals more quickly [28]. In terms of accuracy in affect detection, facial (versus vocal) cues were described as easier to recognize both by children and adults [29, 30], especially the basic emotions [31].

An understanding of how attachment and personality styles influence the recognition of emotions can benefit from the conceptualizations of personality outlined by the postrationalist approach, developed by Vittorio Guidano within the theoretical context of cognitive constructivism [32 - 35]. According to Guidano's model of personality styles, each individual is characterized by a pattern of self-coherence, or Personal Meaning Organization (PMO). PMOs represent arrangements of processes by which individuals form personal meaning-i.e., the subjectivity in self-referring experiences and the development of adaptive behavioral strategies [36, 37]-and thus wholeness and historical continuity through their lifetimes [33 - 35, 38, 39]. From that perspective, psychopathological disorders and symptoms reflect a disruption of selforganization processes; thus, a psychotherapeutic approach focusing on PMOs aims to improve the skills needed to control disordered emotions and develop new, more adaptive behavioral strategies [36, 37].

Attachment relationships are involved in the development of PMOs because the behavioral attachment system drives an individual's adaptive ability toward developing the most useful PMO for achieving or maintaining close proximity to one's caregiver [36, 40, 41]. The adaptive stabilization of a child's PMO depends on how easily they learn to predict the caregiver's behaviors and to perceive the caregiver as being available or not, willing to help or not, and emotionally close or not [42]. When the caregiver's behaviors are stable and predictable, the child learns to easily decode the caregiver's and their own basic feelings of fear, anger, sadness, and happiness. The stability and predictability of the caregiver's emotional conduct equip the child with a strong ability to decode their own internal emotional activations and to interpret, through these emotions, what is happening in the environment (inward experience focus) [43].

When caregivers' behaviors and expressions are more complex, variable, and/or perceived as dependent on external situations and environmental rules, it becomes more challenging for the child to clearly discriminate, decode, and predict caregivers' emotions. Consequently, due to the inconsistency and ambiguity of caregiver response, the child learns to be constantly centered on the external world, to read the environmental signals, and to continuously check the caregiver's emotional attitude in order to decode the situation and to discriminate between rejection and acceptance. Being constantly focused on the environment's signals makes it more difficult for the child to discriminate among internal emotional states, which can only be interpreted with the aid of the external context and by continuously referring to the outside world. As a result, the child's emotional activations move through a preliminary evaluation of environmental messages and requests that consequentially orient recognition of internal states and self-perception and that become essential to perceiving and recognizing internal emotional states (outward experience focus) $[32,42]$.

Accordingly, inwardly-disposed individuals can process emotional stimuli faster than outwardly-disposed ones, since they primarily use bodily reactions and their own internal activations to read the environment, and do not need to cognitively process such stimuli $[43,44]$ or rely on the aid of specific circumstances and the external context to interpret these stimuli [32].

Additionally, the caregiver's ability to provide a strong sense of protection, reassurance, and approval instills in the child the concept of high reciprocity as opposed to low reciprocity, in which the caregiver is distant and imposes rules and principles.

The two primary developmental axes-i.e., caregiver predictability and reciprocity-establish the four main PMOs: the eating disorder organization (outward focus/low predictability, high reciprocity), the obsessive organization (outward focus/low predictability, low reciprocity), the phobic organization (inward focus/high predictability, high reciprocity), and the depressive organization (inward focus/high predictability, low reciprocity) [42].

Individuals with the eating disorder organization display a blurry sense of self due to a propensity to act both on the basis of their internal states and on opinions built on external factors (either persons or situations). Accordingly, their ability to decode basic emotions is cognitively mediated through what is called reflective appraisal [45]. Individuals with the obsessive organization present awareness, conscious behavior, sense of responsibility, order, and coherence. Their behavior and thinking are expected to match abstract principles, and they usually control emotional situations on the basis of analytical and logical skills [40, 46]. Phobic-organized individuals display an automatic appraisal (i.e., immediacy in perception without awareness) of basic emotions-particularly fear-that 
dominates their personality styles and emotional living [32, 34, $44,45,47]$. Lastly, individuals with depressive organization display typical depressive behaviors, affective incompetence, sense of loss, a denial of the importance of the support of others, and a strong sense of self-sufficiency prevails [32].

Evidence supporting the validity of PMO constructs, as operationalized in instruments developed for their assessment (e.g., the Personality Meaning Organization Questionnaire), has been provided through comparisons of inward and outward styles with Cloninger's model of personality and Big Five personality factors [48].

Inward and outward orientations are described as being connected with a putative genetic pattern/basis [49] and associated with variability in the processing of basic emotions, which shows different patterns of emotional activation $[22,44$, 50]. For example, neural activations during the cognitive labeling of threatening facial expressions differ significantly between phobic- and eating disorder-organized individuals [50].

In light of the above considerations, this study sought to investigate how attachment and inward and outward personality styles affect individuals' ability to interpret emotions. Since PMO styles (particularly phobic and eating disorder PMOs) and attachment orientations differ in terms of the immediacy with which basic emotions are processed [15, 18, 44], this study also assessed Reaction Times (RT) in decoding emotions. Lastly, given the little attention to the recognition of emotional voices by the literature, this study adopted vocal emotional stimuli. Two experiments were conducted that involved emotional voice recognition: one assessing perceivers' accuracy, the other assessing their RT.

It is hypothesized that individuals with different attachment styles and with inward versus outward orientations will show significant differences in their ability and their time needed to decode vocal emotional stimuli. Specifically, securely attached individuals are expected to perform better than insecurely attached ones, and inwardly-disposed individuals are expected to perform better than outwardlydisposed ones.

Adults were selected to participate in the experiments because validated measures of inward or outward orientations in the literature are for adults only. In light of evidence indicating women's general superiority in recognizing emotions [22, 51], possible gender effects were also investigated.

\section{STUDY 1}

\subsection{Methods}

\subsubsection{Participants}

The sample consisted of 278 young adults (147 women) with a mean age of 23.16 years ( $S D=2.59$; range: 18 -30 years) attending a university in southern Italy. Participation was voluntary. Inclusion criteria were a signed consent form, age of 18-30 years, good general health, and lack of hearing impairments. Volunteers were excluded if they demonstrated evidence of physical or mental disease that would compromise their participation in or completion of the emotional voice recognition task or had a history of drug abuse or any psychiatric disorders. Inclusion and exclusion were determined following brief interviews upon enrolment.

\subsubsection{Materials and Procedures}

\subsubsection{Attachment}

Attachment style was evaluated with the Italian standardized version of the Experiences in Close Relationships Questionnaire (ECRQ) [52 - 54], a self-report, 36-item questionnaire for investigating feelings of being in close relationships with others, with responses weighted on a 7-point Likert scale $(1=$ strongly disagree, $7=$ strongly agree). Scores reflect two basic dimensions of the attachment style: attachment avoidance (i.e., avoidance of intimacy due to uneasiness with closeness) and attachment anxiety (i.e., anxiety about rejection or abandonment). According to Bartholomew and Horowitz [55], those dimensions give rise to four theoretically distinct attachment styles: secure (i.e., low avoidance and anxiety), insecure-dismissive (i.e., high avoidance and low anxiety), insecure-preoccupied (i.e., low avoidance and high anxiety), and insecure-fearful (i.e., high avoidance and anxiety). The reliability and validity of ECRQ scales are strong $[56,57]$. A validated Italian version of the ECRQ was used in this study [53, 54].

\subsubsection{Inward and Outward Personality}

Inward and outward personality styles were measured with the Personality Meaning Questionnaire (PMQ) [35, 58], a selfreport, 68 -item questionnaire evaluating cognitive themes that characterize the four PMOs of Guidano's [33, 34] basic personality patterns (i.e., psychogenic eating disorder organization, obsessive organization, phobic organization, and depressive organi-zation). The PMQ has 17 items for each PMO, all aimed at gauging feeling, thinking, and acting strategies and none of which refer to possible psychopathologies. Responses are weighted on a 5-point Likert scale $(1=$ completely untrue, $5=$ completely true). The PMQ questionnaire organizes inward individuals as belonging to either the phobic or depressive PMOs and outward individuals as belonging to either psychogenic eating disorder or obsessive PMOs based on the prevalence of one of the four PMQ scales whose total score is at least $10 \%$ higher than the ones obtained by the other scales [48]. PMQ has demonstrated both satisfactory reliability - in terms of internal consistency and test-retest stability - and validity - in terms of content, factorial, convergent, and discriminant validity [48, 58]. In particular, PMQ has shown convergent validity through significant correlations with other validated measures of personality (TCI-125, BFQ, TAS-20, ECRA) [48], as well as internal validity through a PMQ factor structure that was largely consistent with the post-rationalist paradigm that guided its construction [58]. By means of factor analysis, four different factors were found in the items of the questionnaire (as well as in the preliminary version), one for each PMO, explaining about $28 \%$ of the total variance [58, 59]. A validated Italian version of the PMQ was used in this study [50]. 


\subsubsection{Emotion Recognition}

Ability to recognize emotions was assessed by asking participants to listen to 20 emotional vocal utterances: four for each of five emotions (i.e., fear, joy, sadness, surprise, and anger) of the six basic emotions defined by Ekman, Friesen, and Hager [60]. With two uttered by a man and two by a woman, emotional utterances - all selected from the COST 2102 emotional vocal database [61 - 63] —were in Italian and without any emotional semantic content in order to prevent interference with the emotion recognition task. Drawn from Italian film productions, all utterances were contextually embedded in film scripts.

\subsection{Procedure}

In a laboratory setting free of distractions, participants completed and signed consent forms, followed by the ECRQ and PMQ. Next, they were asked to listen to all 20 utterances and assign each utterance one of the five mentioned emotions by checking the corresponding box on the answer grid. Utterances were presented randomly via headphones attached to a personal computer, the screen of which centrally displayed a neutral background with various sound icons that participants were asked to click no more than three times each in order to access the sound.

\subsection{Data Analysis}

The variables of interest were attachment style (secure, insecure-dismissive, insecure-preoccupied, and insecurefearful, according to ECRQ scores), personality style (inward/outward orientation, according to PMQ scores), emotion recognition ability (decoding accuracy, decoding reaction time), and gender. To assess the homogeneity of the scales, Cronbach's alpha $(\alpha)$ was computed. Differences among groups in categorical variables - gender and attachment style, as well as gender and personality organizations - were assessed with the $\chi^{2}$ test, and differences in mean values between genders were evaluated with an independent sample $t$ test. To gauge the significance of the effect of attachment style and inward or outward personality on the accuracy of emotion recognition, a factorial Analysis of Variance (ANOVA) was performed for each of the five emotions in terms of attachment styles and inward or outward personality organizations as between-participant variables. By contrast, the mean of correct answers to the vocal emotion recognition task served as withinparticipant variables. To ensure balanced frequencies of attachment groups, the attachment was treated as a two-level factor $($ secure; insecure $=$ preoccupied + dismissive + fearful $)$. In the case of significant differences between secure and insecure individuals, ANOVA was conducted to distinguish among types of insecurity (i.e., preoccupied, dismissive, and fearful).

Effect sizes $(d)$ of significant changes were calculated.

\section{RESULTS}

\subsection{Sample Characteristics}

Distributions of attachment style and inward/outward classification in the entire sample appear in Table $\mathbf{1}$ (where they are grouped by gender, allowing for comparisons), along with the Cronbach's alpha coefficients, means, and standard deviations for ECRQ and PMQ scores.

ECRQ Avoidance/Anxiety dimensions and PMQ inward/outward scale demonstrated good internal consistency (Table 1).

Participants had greater relationship avoidance than norms for the ECRQ [54] $(M$ norms $=44.05, S D$ norms $=19.40)$ (Cohen's $d=.77$ ). Participants showed greater similarity to norms in the relationship anxiety dimension, and men showed significantly more avoidance in comparison to mean scores of the normative sample $(M$ norms $=59.89, S D$ norms $=20.36$; Cohen's $d=.29$ ) [54] and to mean scores of women assessed in the present study $(\mathrm{t}(276)=5.204, \quad p<.0001)$. No gender differences were found in anxiety mean scores $(\mathrm{t}(276)=-1.041$, $p=$ n.s.) or in the distribution of secure and insecure attachment $\left(\chi^{2}=.662, d f=1, p=\right.$ n.s. $)($ Table $\mathbf{1})$.

Table 1. The percentage (\%) and the number (N) of subjects classified according to attachment style (secure, preoccupied, dismissive, fearful) and personality orientation (inward, outward). ECRQ and PMQ Cronbach's alpha ( $\alpha$ ) coefficients, mean $(M)$ and standard deviations $(S D)$ are given for the total sample $(\mathrm{N}=278)$ and by gender $(\mathrm{N}=131$ men, $\mathrm{N}=147$ women), allowing for gender-based comparisons.

\begin{tabular}{|c|c|c|c|c|}
\hline & & Total Sample & Men & Women \\
\hline Attachment style & & $\%(\mathrm{~N})$ & $\%(\mathrm{~N})$ & $53.7(79)$ \\
\hline Secure & & $51.5(143)$ & $48.9(64)$ & $18.4(27)$ \\
\hline Insecure (preoccupied) & & $18.7(52)$ & $19.1(25)$ & $15(22)$ \\
\hline Insecure (dismissive) & & $14.7(41)$ & $14.5(19)$ & $12.9(19)$ \\
\hline Insecure (fearful) & & $15.1(42)$ & $17.5(23)$ & $M(S D)$ \\
\hline ECRQ & $\alpha$ & $M(S D)$ & $63(S D)$ & $53.37(17.78)$ \\
\hline ECRQ Avoidance & .864 & $58.06(16.68)$ & $65.34(13.58)^{* * *}$ & $\%(16.97)$ \\
\hline ECRQ Anxiety & .853 & $66.56(17.09)$ & $\%(\mathrm{~N})$ & $34.7(51)$ \\
\hline Personality orientation & & $\%(\mathrm{~N})$ & $48.1(63)$ & $65.3(96)^{*}$ \\
\hline Inward & & $41(114)$ & $51.9(68)$ & $M(S D)$ \\
\hline Outward & & $59(164)$ & $M(S D)$ & $2.99(.37)$ \\
\hline PMQ & $\alpha$ & .794 & $2.98(.38)$ & \\
\hline PMQ Inward & & & \\
\hline
\end{tabular}


(Table 1) contd.....

\begin{tabular}{|c|c|c|c|c|}
\hline & & Total Sample & Men & Women \\
\hline PMQ Outward & .830 & $3.21(.42)$ & $3.11(.44)$ & $3.3(.38)^{* * *}$ \\
\hline
\end{tabular}

${ }^{*} p<.05 ; * * p<.01 ; * * * p<.001$

Regarding personality, participants with outward and inward personalities were distributed nearly equally between the secure and insecure attachment categories $\left(\chi^{2}=2.625, d f=\right.$ $1, p=$ n.s.). Outward personality was significantly more prevalent among women than men $\left(\chi^{2}=5.140, d f=1, p=\right.$ .028), as confirmed by higher PMQ outward mean scores in women than in men $(\mathrm{t}(273)=-3.906, p<.0001$, Cohen's $d=.63)$. No gender differences were found in PMQ inward mean scores $(\mathrm{t}(273)=-1.021, p=.308)$ (Table 1$)$.

\subsection{Effects of Gender on Accuracy in Recognizing Vocal Emotions}

By comparing means of correct recognition of emotions among men and women participants, results showed that women significantly outperformed men in interpreting vocal expressions of all emotions tested: joy $(t(276)=-2.340, p=$ $.045)$, fear $(t(276)=-4.620, p=-020)$, anger $(t(276)=-3.048, p$ $<.001)$, surprise $(t(276)=-3.492, p=<.001)$, and sadness $(t(276)=-3.148, p=.044)$.

\subsection{Effects of Attachment and Inward and Outward Personality on Accuracy in Recognizing Vocal Emotions}

A factorial ANOVA on the correct recognition of each of the five emotions showed no significant differences in ability to recognize emotions in vocal expressions between individuals with secure or insecure attachment and inward or outward personality (joy $F(1,2789=2.197, p=$ n.s.; fear $F(1,278)=$ $.258, p=$ n.s.; anger $F(1,278)=.001, p=$ n.s.; surprise $F(1,278)$ $=.672, p=$ n.s.; sadness $F(1,278)=1.286, p=$ n.s.), as shown in Table 2. No interaction effects between attachment style and personality organizations were observed, (joy $F(1,2789=$
3.302, $p=$ n.s.; fear $F(1,278)=2.170, p=$ n.s.; anger $F(1,278)$ $=1.985, p=$ n.s.; surprise $F(1,278)=3.326, p=$ n.s.; sadness $F(1,278)=2.551, p=$ n.s. $)$.

\section{STUDY 2}

\subsection{Methods}

\subsubsection{Participants}

A hundred students (50 women, with a mean age of 24.02 years, $S D=2.58$ ), randomly selected among participants in Study 1 , were asked to assess the mentioned emotional utterances by following a different procedure in order to measure their answering RT.

\subsection{Materials and Procedure}

All methods in Study 2 were identical to those reported for Study 1 except that participants were instructed to listen to vocal emotional expressions using a computerized task programmed with SuperLabPro [64], with which both vocal stimulus's assigned labels and participants' RT (i.e., time elapsed from presentation of the stimulus to selection of emotion) were recorded. To assess the significance of attachment style and inward or outward personality on RT, a factorial ANOVA analysis was performed for each of the five emotions with attachment style and inward or outward personality organizations as between-participant variables, and RT as within-participant variables. The mean RT for each of the five emotional categories (i.e., mean time to answer all four stimuli of joy, fear, anger, surprise, and sadness) was computed.

Table 2. Mean $(M)$ and standard deviations $(S D)$ computed by the number of correct responses to emotional vocal stimuli, obtained for individuals with secure and insecure attachment style and inward or outward personality organizations.

\begin{tabular}{|c|c|c|c|c|}
\hline & & & \multicolumn{2}{|c|}{ Attachment style } \\
\hline & & Secure & $M(S D)$ & Insecure \\
\hline Emotion in voice & Inward or outward & $M(S D)$ & $3.24(.881)$ & $3.39(.793)$ \\
\hline Joy & Inward & $3.56(.639)$ & $3.44(.707)$ & $3.43(.693)$ \\
\hline & Outward & $3.43(.685)$ & $3.35(.795)$ & $3.32(.905)$ \\
\hline Fear & Total & $3.48(.670)$ & $3.18(1.064)$ & $3.38(.909)$ \\
\hline & Inward & $3.48(.641)$ & $3.40(.893)$ & $3.66(.751)$ \\
\hline Anger & Outward & $3.37(.927)$ & $3.30(.978)$ & $3.63(.761)$ \\
\hline & Total & $3.41(.834)$ & $3.60(.877)$ & $3.53(.904)$ \\
\hline & Inward & $3.73(.564)$ & $3.70(.701)$ & $3.63(.784)$ \\
\hline Surprise & Outward & $3.57(.805)$ & $3.65(.785)$ & $3.40(1.093)$ \\
\hline
\end{tabular}




\section{RESULTS}

\subsection{Sample Characteristics}

By ECRQ scores, $44 \%$ of participants exhibited a secure attachment style $(n=44), 21 \%$ were dismissive $(n=21), 20 \%$ were preoccupied $(n=20)$, and $15 \%$ were fearful $(n=15)$. By PMQ scores, $45 \%$ of them had an inward and $55 \%$ an outward personality.

Differences in gender $\left(\chi^{2}=1.010, p=\right.$ n.s. $)$ and attachment style $\left(\chi^{2}=1.286, p=\right.$ n.s. $)$ between the inward and outward groups were not significant, nor were differences in gender $\left(\chi^{2}\right.$ $=0.000, p=$ n.s. $)$ and personality styles $\left(\chi^{2}=1.286, p=\right.$ n.s. $)$ between securely and insecurely attached individuals.

\subsection{Effects of Gender, Attachment Style, and Inward or Outward Personality on Accuracy in Recognizing Vocal Emotions}

A two tailed $t$-test on men's and women's recognition accuracy for each emotion revealed no effects of gender (joy $t(98)=.000, p=$ n.s., fear $t(98)=-.882, p=$ n.s., anger $t(98)=$ $.176, p=$ n.s., surprise $t(98)=.000, p=$ n.s., sadness $t(98)=$ $.647, p=$ n.s.). A factorial ANOVA analysis, with the dependent variable of accuracy in decoding emotional vocal stimuli, showed no significant effects for either attachment style (joy $F(1,100)=.362, p=$ n.s., fear $F(1,100)=1.038, p=$ n.s.; anger $F(3,100)=.701, p=$ n.s.; surprise $F(3,100)=2.188$, $p=$ n.s.; sadness $F(3,100)=3.979, p=$ n.s. $)$ or personality trait type (joy $F(3,100)=.250, p=$ n.s., fear $F(3,100)=.160, p=$ n.s.; anger $F(3,100)=.087, p=$ n.s.; surprise $F(3,100)=.118, p$ $=$ n.s.; sadness $F(3,100)=.031, p=$ n.s.). No interactions between attachment styles and personality organizations emerged, either $($ joy $F(3,100)=3.995, p=$ n.s., fear $F(3,100)=$
$.482, p=$ n.s.; anger $F(3,100)=.360, p=$ n.s.; surprise $F(3,100)$ $=1.102, p=$ n.s.; sadness $F(3,100)=.879, p=$ n.s. $)$.

\subsection{Effects of Attachment and Inward or Outward} Personality on Reaction Time in Decoding Vocal Emotions

A factorial ANOVA analysis on participants' RT in decoding vocal expressions of joy showed that both secure and inward-focused individuals were significantly faster than insecure $\left(F(1,100)=4.580, p=.035, n^{2}=.046\right)$ and outwardfocused ones $\left(F(1,100)=6.671, p=.011, n^{2}=.065\right)$. Securely attached individuals were also faster than insecurely attached ones in identifying vocal expressions of anger in people's voices $\left(F(3,100)=7.115, p=.009, n^{2}=.069\right)$, as shown in Table 3.

When the four attachment styles were considered (i.e., secure, dismissive, preoccupied, and fearful), ANOVA confirmed that attachment style and personality organizations $\left(F(3,100)=3.988, p=.010, n^{2}=.115\right)$ affected participants' $\mathrm{RT}$ in decoding joy $\left(F(1,100)=15.519, p<.001, n^{2}=.144\right)$, and attachment style affected their ability to decode anger in people's voices $\left(F(3,100)=4.611, p=.005, n^{2}=.131\right)$. ANOVA also revealed the interaction of attachment style and personality organizations in identifying joy $(F(3,100)=5.566$, $\left.p=.001, n^{2}=.154\right)$, which showed the shortest RT, obtained by the dismissive-inward group $(M=5.55 \mathrm{~s}, S D=.731)$. Post hoc comparisons among groups with Duncan's multiplecomparison procedures revealed that the RT of securely attached individuals (6.03) to joy did not differ from that achieved by dismissive (6.27) and preoccupied (6.77) individuals, yet were significantly shorter than that achieved by fearful (6.98) ones. Fearful individuals also did not differ from dismissive and preoccupied ones regarding time to interpret joy in people's voices.

Table 3. Mean $(M)$ reaction time and standard deviations $(S D)$ among securely or insecurely attached individuals with either inward or outward personality organizations; all times in seconds.

\begin{tabular}{|c|c|c|c|c|}
\hline & & \multicolumn{3}{|c|}{ Attachment style } \\
\hline & & Secure & & Insecure \\
\hline Emotion in voice & Inward or outward & $M(S D)$ & $M(S D)$ & Total \\
\hline \multirow[t]{3}{*}{ Joy } & Inward & $5.78(.691)$ & $6.05(1.26)$ & $5.95(1.08)$ \\
\hline & Outward & $6.19(1.34)$ & $7.21(2.06)$ & $6.71(1.81)^{*}$ \\
\hline & Total & $6.03(1.14)$ & & $6.63(1.79)^{*}$ \\
\hline \multirow[t]{3}{*}{ Fear } & Inward & $4.88(2.1)$ & $5.19(1.8)$ & $5.07(1.9)$ \\
\hline & Outward & $4.77(1.78)$ & $5.29(1.8)$ & $5.03(1.79)$ \\
\hline & Total & $4.82(1.9)$ & & $5.24(1.78)$ \\
\hline \multirow[t]{3}{*}{ Anger } & Inward & $5.77(7.92)$ & $7.01(2.03)$ & $6.55(1.77)$ \\
\hline & Outward & $6.05(1.07)$ & $6.43(1.5)$ & $6.24(1.31)$ \\
\hline & Total & $5.94(.97)$ & & $6.72(1.79) * *$ \\
\hline \multirow[t]{3}{*}{ Surprise } & Inward & $6.01(2.74)$ & $5.6(1.33)$ & $5.77(1.96)$ \\
\hline & Outward & $6.33(2.99)$ & $6.24(1.97)$ & $6.28(2.5)$ \\
\hline & Total & $6.2(2.87)$ & $5.93(1.7)$ & \\
\hline \multirow[t]{3}{*}{ Sadness } & Inward & $8.42(3.47)$ & $7.98(2.9)$ & $8.14(3.09)$ \\
\hline & Outward & $8.38(2.57)$ & $8.19(2.49)$ & $8.28(2.5)$ \\
\hline & Total & $8.4(2.91)$ & $8.08(2.67)$ & \\
\hline
\end{tabular}

${ }^{*} p<.05 ; * * p<.01 ; * * * p<.001$ 
Table 4. Mean $(M)$ reaction times and standard deviations $(S D)$ in correctly responding to vocal emotional stimuli among securely or insecurely attached individuals with either inward or outward personality organizations; all times in seconds.

\begin{tabular}{|c|c|c|c|c|}
\hline & & \multicolumn{3}{|c|}{ Attachment style } \\
\hline & & Secure & Insecure & \\
\hline Emotion in voice & Inward or outward & $M(S D)$ & $M(S D)$ & Total \\
\hline \multirow[t]{3}{*}{ Joy } & Inward & $5.81(.75)$ & $5.69(.66)$ & $5.75(.69)$ \\
\hline & Outward & $6.08(1.14)$ & $6.69(1.93)$ & $6.4(1.62)$ \\
\hline & Total & $5.96(.98)$ & $6.26(1.59)$ & \\
\hline \multirow[t]{3}{*}{ Fear } & Inward & $3.84(.93)$ & $5.14(1.71)$ & $4.62(1.57)$ \\
\hline & Outward & $4.35(1.75)$ & $4.78(1.83)$ & $4.58(1.78)$ \\
\hline & Total & $4.14(1.46)$ & $4.95(1.76)$ & \\
\hline \multirow[t]{3}{*}{ Anger } & Inward & $5.62(.55)$ & $7.10(2.21)$ & $6.48(1.86)$ \\
\hline & Outward & $6.01(1.13)$ & $6.04(.83)$ & $6.03(.98)$ \\
\hline & Total & $5.86(.95)$ & $6.54(1.71)^{*}$ & \\
\hline \multirow[t]{3}{*}{ Surprise } & Inward & $5.67(.933)$ & $5.22(.74)$ & $5.38(.83)$ \\
\hline & Outward & $5.45(1.99)$ & $5.75(1.37)$ & $5.65(1.57)$ \\
\hline & Total & $5.56(1.52)$ & $5.50(1.14)$ & \\
\hline \multirow[t]{3}{*}{ Sadness } & Inward & $8.24(3.9)$ & $7.19(2.01)$ & $7.64(2.97)$ \\
\hline & Outward & $8.20(2.63)$ & $7.66(1.80)$ & $7.93(2.24)$ \\
\hline & Total & $8.22(3.5)$ & $7.44(1.89)$ & \\
\hline
\end{tabular}

$* p<.05 ; * * p<.01 ; * * * p<.001$

ANOVA was not performed on insecurely (i.e., dismissive, preoccupied, and fearful) attached subgroups given the few participants in those categories.

Concerning differences among groups in terms of RT in decoding anger in people's voices, post hoc analysis revealed that secure individuals' RT (5.94) did not differ from dismissive ones' (6.05) and was significantly shorter than preoccupied (7.02) and fearful (7.25) individuals.

A factorial ANOVA was performed to identify any differences in RT among groups of participants who correctly labeled all vocal stimuli for each emotion, with mean RT for correct answers as the dependent variable. The numbers of participants who gave entirely correct answers for each emotion were as follows: joy $(n=67)$, fear $(n=55)$, anger $(n=$ $82)$, surprise $(n=59)$, and sadness $(n=68)$. ANOVA revealed that securely attached individuals were significantly faster than insecurely attached ones in correctly identifying anger in people's voices $\left(F(1,82)=6.017, p=.016, n^{2}=.072\right)$. Personality organizations interacted with attachment style $\left(F(1,82)=5.576, p=.021, n^{2}=.067\right)$, which indicated that securely attached individuals with inward personalities were faster at decoding anger in people's voices (Table 4).

ANOVA was not performed on insecurely (i.e., dismissive, preoccupied, and fearful) attached subgroups given the few participants in those categories.

\section{DISCUSSION}

The study presented here aimed to extend previous findings on the ability to decode vocal emotional stimuli as a function of attachment style and inward or outward personality dimensions [65 - 67].

From a theoretical perspective, the results support, within the theoretical background of cognitive constructivism, the role of concepts such as inward and outward and PMO as able to explain individual differences in processing basic emotions.
Since the recognition of emotion falls within the basic skills upon which typical social interactions are based, the findings can be useful to enhance the comprehension of personalityrelated factors involved in the context of daily social interactions and in patient-psychotherapist interactions.

The obtained results partially supported the hypotheses. Despite no differences in the emotion recognition accuracy between securely and insecurely attached participants and inward/ outward focused individuals in Study 1, both securely attached and inward-focused individuals showed different emotion recognition RT compared to individuals in the other groups. Findings from Study 2 suggest that secure attachment reduces the time an individual needs to interpret an emotional vocal stimulus conveying joy (i.e., securely attached individuals answered significantly faster than fearful ones) and anger (i.e., securely attached individuals answered significantly faster than fearful and preoccupied ones) compared to the time needed by insecure attached ones. Similarly, inwardly disposed individuals more quickly responded to joyful vocal stimuli than outwardly disposed ones.

Secondary analyses performed on data representing individuals who provided correct answers in emotion recognition labeling revealed that securely attached individuals, especially if inward-focused, are faster than insecure ones in correctly identifying vocal stimuli conveying anger.

Such results provide evidence that secure attachment styles and inward personality organizations facilitate an individual's understanding of emotions by shortening the time necessary to assign anger and joy to vocal stimuli, as well as to correctly assign anger to vocal stimuli. As research has shown, how caregivers and parents respond to children affects both the attachment style that children will develop and their emotional 
competencies as adults $[1,2,8,9]$. In line with an attachment theory perspective, secure individuals are thought to be confident with their own and others' emotional behaviors (i.e., are socially advantaged individuals). Joy and anger, as strongly socially situated emotions, require a faster adaptive response to challenging social situations [68]. Therefore, it is hypothesized here that secure individuals are equipped to more quickly detect social emotions, such as joy and anger, from vocal emotional stimuli. Such would not be the case for sadness, fear, and disgust, however, they do not need social competences.

Securely attached individuals were also faster in correctly decoding anger. As an explanation, it is plausible to assume that children with secure attachment, given the confidence that they develop due to their caregivers' ability to support them in any circumstances, might not experience anger as threatening. Anger is a functional response to another's negative attachment behaviors, and securely attached children learn to keenly process anger as a temporary, reversible negative behavior and are confident in having "suitable responses for successfully dealing with these behaviors" [69]. Such might not be the case for sadness and fear, which are less temporary and reversible behaviors than anger, and even secure individuals may not have suitable responses for successfully dealing with them. In support of that assumption, evidence suggests that securely attached individuals can easily recognize angry facial expressions as well as those with any negative valence [70, 71]. Nonetheless, and in contrast to the present results, other studies have described insecure maltreated children as being more likely to identify blended expressions as angry [72] and better at scrutinizing angry signals of rejection and disapproval [73]. Those inconsistencies can be attributed to differences in stimuli adopted, being mainly visual in the mentioned studies and auditory in the study reported here. Nevertheless, empirical research on the role that insecure attachment plays in individuals' ability to interpret emotional facial and vocal expressions has not yet produced conclusive results $[15,18$ 20, 65 - 67].

Regarding the role of inward personality, the findings of the study were consistent with the post-rationalist assumption that basic emotions are usually perceived with immediacy by inwardly disposed individuals, yet tend to be cognitively mediated by outwardly disposed ones $[35,44]$. The absence of differences between personality styles and the ability to interpret emotional vocal expressions of fear, sadness, and surprise could suggest that individual characteristics play a different, not fully evaluated, role in such tasks.

A theoretical and practical implication of the present study is the improved comprehension of the role that personality dimensions play in individuals' ability to recognize emotions. Outward and inward PMOs, to our knowledge, have never been investigated in relation to individuals' attachment styles in order to identify matching abilities, including similar attitudes or differences in ways of decoding emotional expressions, if not both. In that sense, the study reported here presents an original attempt to move beyond traditional schemes that relate emotional intelligence to attachment styles and visual stimuli only. In particular, researchers have neglected the subjectivity involved in the self-referring experience and developing adaptive behavioral strategies (e.g., inward and outward PMOs) and vocal emotional expressions, as well as failed to define appropriate relationships among them.

These results suggest that the human ability to decode emotions is shaped by individual characteristics, which raises the need for further investigations that also account for the effects of communication modes.

\section{CONCLUSION}

The study posed some limitations. For one, because its sample was small, replication in a larger sample is advised. Second, selection bias might have occurred in the sample recruitment process: participants were university students recruited on a voluntary basis, and all of them were from the same geographic area. It would be useful to compare the present results with different classes of the general population. In addition, a self-report instrument (i.e., the ECRQ) was used to assess attachment orientation among healthy adults, which limits the generalizability of the findings. The study did not examine other significant variables that could affect attachment style (e.g., abuse, neglect, loss, and other personality traits) and that, in turn, could affect individuals' ability to recognize emotions and might partly explain individual differences (or lack thereof) in the analysis of the variables of interest.

Additional data and investigations on the topic are, therefore, recommended.

\section{ETHICS APPROVAL AND CONSENT TO PARTI- CIPATE}

The study protocol was reviewed and approved by the local ethics committee of University of Campania "L. Vanvitelli”, Department of Psychology, Salerno, Italy.

\section{HUMAN AND ANIMAL RIGHTS}

No animals were used in this research. All human research procedures followed were in accordance with the ethical standards of the committee responsible for human experimentation (institutional and national), and with the Helsinki Declaration of 1975, as revised in 2013.

\section{CONSENT FOR PUBLICATION}

A written informed consent was taken from all the participants when they were enrolled.

\section{AVAILABILITY OF DATA AND MATERIALS}

Not applicable.

\section{FUNDING}

The research leading to these results has received funding from the EU H2020 research and innovation program under grant agreement N. 769872 (EMPATHIC) and N. 823907 (MENHIR); the project SIROBOTICS that received funding from Italian MIUR, PNR 2015-2020, D.D. 1735, 13/07/2017; and the projects ANDROIDS and DiabEat1, both funded by the program V:ALERE 2019 Università della Campania "Luigi Vanvitelli”, D.R. 906 del 4/10/2019, prot. n. 157264, $17 / 10 / 2019$. 


\section{CONFLICT OF INTEREST}

The author declares no conflict of interest, financial or otherwise.

\section{ACKNOWLEDGEMENTS}

The authors thank Dr. Maria Ceraso and Dr. Francesca Di Gennaro for their help in data collection, and all participants who agreed to take part in the investigation.

\section{REFERENCES}

[1] Attachment. Bowlby J. Attachment and lossNew York, NY: Basic Books 1969; 1.

[2] Bowlby J. A secure base: Parent-child attachment and healthy human development. New York, NY: Basic Books 1988.

[3] Grossmann KE, Grossmann K. The wider concept of attachment in cross-cultural research. Hum Development 1990; 33: 31-47. [http://dx.doi.org/10.1159/000276501]

[4] Mikulincer M, Orbach I. Attachment styles and repressive defensiveness: the accessibility and architecture of affective memories. J Pers Soc Psychol 1995; 68(5): 917-25.

[http://dx.doi.org/10.1037/0022-3514.68.5.917] [PMID: 7776187]

[5] Mikulincer M, Shaver PR, Pereg D. Attachment theory and affect regulation: The dynamics, development, and cognitive consequences of attachment-related strategies. Motiv Emot 2003; 27: 77-102. [http://dx.doi.org/10.1023/A:1024515519160]

[6] Soken NH, Pick AD. Intermodal perception of happy and angry expressive behaviors by seven-month-old infants. Child Dev 1992; 63(4): 787-95

[http://dx.doi.org/10.2307/1131233] [PMID: 1505240]

[7] Young-Browne G, Rosenfeld HM, Horowitz FD. Infant discrimination of facial expressions. Child Dev 1977; 48: 555-62. [http://dx.doi.org/10.2307/1128653]

[8] Fonagy P, Target M. Attachment and reflective function: their role in self-organization. Dev Psychopathol 1997; 9(4): 679-700. [http://dx.doi.org/10.1017/S0954579497001399] [PMID: 9449001]

[9] Harris PL. Individual differences in understanding emotion: the role of attachment status and psychological discourse. Attach Hum Dev 1999; 1(3): $307-24$

[http://dx.doi.org/10.1080/14616739900134171] [PMID: 11708229]

[10] Mill A, Allik J, Realo A, Valk R. Age-related differences in emotion recognition ability: a cross-sectional study. Emotion 2009; 9(5): 619-30.

[http://dx.doi.org/10.1037/a0016562] [PMID: 19803584]

[11] Realo A, Allik J, No lvak A, et al. Mind-reading ability: Beliefs and performance. J Res Pers 2003; 37: 420-45. [http://dx.doi.org/10.1016/S0092-6566(03)00021-7]

[12] Carton JS, Kessler EA, Pape CL. Nonverbal decoding skills and relationship well-being in adults. J Nonverbal Behav 1999; 23: 91-100. [http://dx.doi.org/10.1023/A:1021339410262]

[13] Lane RD, Sechrest L, Riedel R, Shapiro DE, Kaszniak AW. Pervasive emotion recognition deficit common to alexithymia and the repressive coping style. Psychosom Med 2000; 62(4): 492-501.

[http://dx.doi.org/10.1097/00006842-200007000-00007] [PMID: 10949094]

[14] Magai C, Distel N, Liker R. Emotion socialisation, attachment, and patterns of adult emotional traits. Cogn Emotion 1995; 9: 461-81. [http://dx.doi.org/10.1080/02699939508408976]

[15] Niedenthal PM, Brauer M, Robin L, Innes-Ker ÅH. Adult attachment and the perception of facial expression of emotion. J Pers Soc Psychol 2002; 82(3): 419-33

[http://dx.doi.org/10.1037/0022-3514.82.3.419] [PMID: 11902625]

[16] Noller P, Feeney JA. Relationship satisfaction, attachment, and nonverbal accuracy in early marriage. J Nonverbal Behav 1994; 18 : 199-221.

[http://dx.doi.org/10.1007/BF02170026]

[17] Suslow T, Dannlowski U, Arolt V, Ohrmann P. Adult attachment avoidance and automatic affective response to sad facial expressions. Aust J Psychol 2010; 62: 181-7.

[http://dx.doi.org/10.1080/00049530903567203]

[18] Chris Fraley R, Niedenthal PM, Marks M, Brumbaugh C, Vicary A. Adult attachment and the perception of emotional expressions: probing the hyperactivating strategies underlying anxious attachment. J Pers 2006; 74(4): 1163-90. [http://dx.doi.org/10.1111/j.1467-6494.2006.00406.x]

[PMID: 16787432]

[19] Kafetsios K, Andriopoulos P, Papachiou A. Relationship status moderates avoidant attachment differences in positive emotion decoding accuracy. Pers Relatsh 2014; 21: 191-205.

[http://dx.doi.org/10.1111/pere.12026]

[20] Maier MA, Bernier A, Pekrun R, Zimmermann P, Strasser K, Grossmann KE. Attachment state of mind and perceptual processing of emotional stimuli. Attach Hum Dev 2005; 7(1): 67-81.

[http://dx.doi.org/10.1080/14616730500039606] [PMID: 15981616]

[21] Brumariu LE, Kerns KA, Seibert AC. Mother-child attachment, emotion regulation, and anxiety symptoms in middle childhood. Pers Relatsh 2012; 19: 569-85.

[http://dx.doi.org/10.1111/j.1475-6811.2011.01379.x]

[22] Colle L, Del Giudice M. Patterns of attachment and emotional competence in middle childhood. Soc Dev 2011; 20: 51-72.

[http://dx.doi.org/10.1111/j.1467-9507.2010.00576.x]

[23] Brumariu LE. Parent-child attachment and emotion regulation. New Dir Child Adolesc Dev 2015; 2015(148): 31-45.

[http://dx.doi.org/10.1002/cad.20098] [PMID: 26086126]

[24] Riviello MT, Esposito A. On the perception of dynamic emotional expressions: A cross-cultural comparison. Netherlands: Springer 2016; Vol. 6.

[http://dx.doi.org/10.1007/978-94-024-0887-4]

[25] Flom R, Bahrick LE. The development of infant discrimination of affect in multimodal and unimodal stimulation: The role of intersensory redundancy. Dev Psychol 2007; 43(1): 238-52. [http://dx.doi.org/10.1037/0012-1649.43.1.238] [PMID: 17201522]

[26] Sauter DA, Eisner F, Calder AJ, Scott SK. Perceptual cues in nonverbal vocal expressions of emotion. Q J Exp Psychol (Hove) 2010; 63(11): 2251-72.

[http://dx.doi.org/10.1080/17470211003721642] [PMID: 20437296]

[27] Grosbras MH, Ross PD, Belin P. Categorical emotion recognition from voice improves during childhood and adolescence. Sci Rep 2018; 8(1): 14791 .

[http://dx.doi.org/10.1038/s41598-018-32868-3] [PMID: 30287837]

[28] Recanzone GH. Interactions of auditory and visual stimuli in space and time. Hear Res 2009; 258(1-2): 89-99.

[http://dx.doi.org/10.1016/j.heares.2009.04.009] [PMID: 19393306]

[29] Chronaki G, Hadwin JA, Garner M, Maurage P, Sonuga-Barke EJ The development of emotion recognition from facial expressions and non-linguistic vocalizations during childhood. Br J Dev Psychol 2015; 33(2): 218-36.

[http://dx.doi.org/10.1111/bjdp.12075] [PMID: 25492258]

[30] Nelson NL, Russell JA. Preschoolers' use of dynamic facial, bodily, and vocal cues to emotion. J Exp Child Psychol 2011; 110(1): 52-61. [http://dx.doi.org/10.1016/j.jecp.2011.03.014] [PMID: 21524423]

[31] Calvo RA, D'Mello S. Affect detection: An interdisciplinary review of models, methods, and their applications. IEEE Trans Affect Comput 2010; 1: 18-37.

[http://dx.doi.org/10.1109/T-AFFC.2010.1]

[32] Arciero G, Gaetano P, Maselli P, Gentili N. Identity, personality and emotional regulation.Cognition and psychotherapy. New York, NY: Springer 2004; pp. 7-18.

[33] Guidano VF. Complexity of the self. New York, NY: Guilford 1987.

[34] Guidano VF. The self in progress. New York, NY: Guilford 1991.

[35] Picardi A. First steps in the assessment of cognitive-emotional organisation within the framework of Guidano's model of the self. Psychother Psychosom 2003; 72(6): 363-5. [http://dx.doi.org/10.1159/000073037] [PMID: 14526143]

[36] Nardi B, Bellantuono C. A new adaptive and evolutionary conceptualization of the personal meaning organization (PMO) framework. Eur Psychother 2008; 8: 5-16.

[37] Nardi B, Pannelli G. A tribute to Vittorio F. Guidano (1944-1999). Eur Psychother 2001; 2: 18-9.

[38] Guidano VF. A constructivistic outline of human knowing processes.Cognitive and constructive psychotherapies: Theory, research and practice. New York, NY: Springer 1995; pp. 93-108. [http://dx.doi.org/10.1037/10170-004]

[39] Guidano VF, Liotti G. Cognitive processes and emotional disorders. New York, NY: Guilford 1983.

[40] Nardi B, Francesconi G, Catena-Dell'osso M, Bellantuono C. Adolescent depression: clinical features and therapeutic strategies. Eur Rev Med Pharmacol Sci 2013; 17(11): 1546-51. [PMID: 23771545]

[41] Nardi B, Martini MG, Arimatea E, et al. Postpartum pain in relation with personal meaning organization. Minerva Ginecol 2015; 67(6): 
507-13.

[PMID: 27191016]

[42] Nardi B, Arimatea E, Vernice M, Bellantuono C. How subjectivity can be investigated in the post-rationalist cognitive approach: Clinical and psycho-diagnostic tools. Int J Psychol Stud 2012; 4: 174.

[http://dx.doi.org/10.5539/ijps.v4n2p174]

[43] Nardi B, Rezzonico G, Bellantuono C. Toward a scientific framework for the personal meaning organization (PMO) paradigm: Neuroimaging and genetic studies. Quaderni Italiani di Psichiatria 2010; 29: 81-8.

[http://dx.doi.org/10.1016/j.quip.2010.07.003]

[44] Bertolino A, Arciero G, Rubino V, et al. Variation of human amygdala response during threatening stimuli as a function of 5 'HTTLPR genotype and personality style. Biol Psychiatry 2005; 57(12): 1517-25. [http://dx.doi.org/10.1016/j.biopsych.2005.02.031] [PMID: 15953488]

[45] Ekman P. Emotions revealed: Recognizing faces and feelings to improve communication and emotional life. New York, NY: Henry Holt \& Company 2003.

[46] Poletti B, Carelli L, Lafronza A, et al. Cognitive-constructivist approach in medical settings: The use of Personal Meaning Questionnaire for neurological patients' personality investigation. Front Psychol 2017; 8: 582.

[http://dx.doi.org/10.3389/fpsyg.2017.00582] [PMID: 28443057]

[47] Arciero G, Guidano VF. Experience, explanation and the quest for coherence. Washington, DC: American Psychological Association 2000 .

[http://dx.doi.org/10.1037/10368-005]

[48] Picardi A, Gaetano P, Toni A, Caroppo E, Arciero G. Sostegno alla teoria delle "organizzazioni di significato personale" da altre elaborazioni teoriche nell'area della personalità: uno studio di validità convergente del QSP. Riv Psichiatr 2004; 39: 112-24.

[49] Nardi B, Marini A, Turchi C, Arimatea E, Tagliabracci A, Bellantuono C. Role of 5-HTTLPR polymorphism in the development of the inward/outward personality organization: a genetic association study. PLoS One 2013; 8(12)e82192

[http://dx.doi.org/10.1371/journal.pone.0082192] [PMID: 24358153]

[50] Rubino V, Blasi G, Latorre V, et al. Activity in medial prefrontal cortex during cognitive evaluation of threatening stimuli as a function of personality style. Brain Res Bull 2007; 74(4): 250-7.

[http://dx.doi.org/10.1016/j.brainresbull.2007.06.019] [PMID: 17720547]

[51] McClure EB. A meta-analytic review of sex differences in facial expression processing and their development in infants, children, and adolescents. Psychol Bull 2000; 126(3): 424-53.

[http://dx.doi.org/10.1037/0033-2909.126.3.424] [PMID: 10825784]

[52] Brennan KA, Clark CL, Shaver PR. Self-report measurement of adult attachment: An integrative overview.Attachment theory and close relationships New York, NY. Guilford 1998; pp. 46-76.

[53] Picardi A, Bitetti D, Puddu P, Pasquini P. La scala "Experiences in Close Relationships" (ECL), un nuovo strumento per la valutazione dell'attaccamento negli adulti: Traduzione, adattamento, e validazione della versione italiana. Riv Psichiatr 2000; 114-20.

[54] Picardi A, Vermigli P, Toni A, D’Amico R, Bitetti D, Pasquini P. Further evidence of the validity of the Italian version of the questionnaire "Experiences in Close Relationships" (ECR), a selfreport instrument to assess adult attachment. Ital J Psychopathol 2002; 8: $12-8$.

[55] Bartholomew K, Horowitz LM. Attachment styles among young adults: a test of a four-category model. J Pers Soc Psychol 1991; 61(2): 226-44.

[http://dx.doi.org/10.1037/0022-3514.61.2.226] [PMID: 1920064]

[56] Fraley RC, Waller NG, Brennan KA. An item response theory analysis of self-report measures of adult attachment. J Pers Soc Psychol 2000;
78(2): 350-65.

[http://dx.doi.org/10.1037/0022-3514.78.2.350] [PMID: 10707340]

[57] Sibley CG, Liu JH. Short-term temporal stability and factor structure of the revised experiences in close relationships (ECR-R) measure of adult attachment. Pers and Indiv Differ 2004; 36: 969-75.

[http://dx.doi.org/10.1016/S0191-8869 (03)00165-X]

[58] Picardi A, Mannino G, Arciero G, et al. Costruzione e validazione del QSP, uno strumento per la valutazione dello stile di personalità secondo la teoria delle "organizzazioni di significato personale.". Riv Psichiatr 2003; 38: 13-34.

[59] Picardi A, Le Mannino G. "organizzazioni di significato personale": verso una validazione empirica. Riv Psichiatr 2001; 36: 224-33. [http://dx.doi.org/10.1708/186.1956]

[60] Ekman P, Friesen WV, Hager JC. The facial action coding system. 2nd ed. Salt Lake City, UT: Weidenfeld \& Nicolson 2002.

[61] Esposito A. The perceptual and cognitive role of visual and auditory channels in conveying emotional information. Cognit Comput 2009; 1 : 268-78.

[http://dx.doi.org/10.1007/s12559-009-9017-8]

[62] Esposito A, Riviello MT, Di Maio G. The COST 2102 Italian audio and video emotional database. In: Apolloni B, Bassi S, Morabito CF, Eds. WIRN 09: Proceedings of the 19th Italian Workshop on Neural Nets. 2009 May 28-30; Vietri sul Mare, Salerno, Italy. Amsterdam, the Netherlands: IOS Press 2009; pp. 51-61.

[63] Esposito A, Riviello MT. The new Italian audio and video emotional database.COST 2102 LNCS. Heidelberg, Germany: Springer 2010; pp. 406-22.

[http://dx.doi.org/10.1007/978-3-642-12397-9_35]

[64] Cedrus Corporation. SuperLab Pro: Experimental Laboratory Software. San Pedro, CA: Author 2001. Computer software

[65] Esposito A, Palumbo D, Troncone A. The influence of the attachment style on the decoding accuracy of emotional vocal expressions. Cognit Comput 2014; 6: 699-707. a

[http://dx.doi.org/10.1007/s12559-014-9292-x]

[66] Esposito A, Palumbo D, Troncone A. Emotional consequences of the interaction between inward/outward identities and attachment style In: Cognitive Infocommunications, 2014 5th IEEE Conference on Vietri sul mare, Salerno. Italy. IEEE 2014; pp. 263-6.

[67] Esposito A, Palumbo D, Troncone A. Effects of narrative identities and attachment style on the individual's ability to categorize emotional voices. 2015.

[http://dx.doi.org/10.1007/978-3-319-18164-6_25]

[68] Nesse RM, Ellsworth PC. Evolution, emotions, and emotional disorders. Am Psychol 2009; 64(2): 129-39.

[http://dx.doi.org/10.1037/a0013503] [PMID: 19203145]

[69] Mikulincer M. Adult attachment style and individual differences in functional versus dysfunctional experiences of anger. J Pers Soc Psychol 1998; 74(2): 513-24.

[http://dx.doi.org/10.1037/0022-3514.74.2.513] [PMID: 9491590]

[70] Laible DJ, Thompson RA. Attachment and emotional understanding in preschool children. Dev Psychol 1998; 34(5): 1038-45.

[http://dx.doi.org/10.1037/0012-1649.34.5.1038] [PMID: 9779749]

[71] Steele H, Steele M, Croft C. Early attachment predicts emotion recognition at 6 and 11 years old. Attach Hum Dev 2008; 10(4): 379-93.

[http://dx.doi.org/10.1080/14616730802461409] [PMID: 19016048]

[72] Pollak SD, Sinha P. Effects of early experience on children's recognition of facial displays of emotion. Dev Psychol 2002; 38(5): 784-91.

[http://dx.doi.org/10.1037/0012-1649.38.5.784] [PMID: 12220055]

[73] Cassidy J. Emotion regulation: influences of attachment relationships. Monogr Soc Res Child Dev 1994; 59(2-3): 228-49.

[http://dx.doi.org/10.1111/j.1540-5834.1994.tb01287.x] [PMID: 7984163]

\section{(C) 2020 Esposito and Troncone.}

This is an open access article distributed under the terms of the Creative Commons Attribution 4.0 International Public License (CC-BY 4.0), a copy of which is available at: (https://creativecommons.org/licenses/by/4.0/legalcode). This license permits unrestricted use, distribution, and reproduction in any medium, provided the original author and source are credited. 